\title{
A Study of Factors Influencing on Passive and Active Acceptance of Home Energy Management Services with Internet of Things
}

\author{
Chankook Park* $*$ and Min Jeong * \\ Energy Industry Research Group, Korea Energy Economics Institute (KEEI), Ulsan 405-11, Korea \\ * Correspondence: green@keei.re.kr (C.P.); jm5312@keei.re.kr (M.J.)
}

check for updates

Citation: Park, C.; Jeong, M. A Study of Factors Influencing on Passive and Active Acceptance of Home Energy Management Services with Internet of Things. Energies 2021, 14, 3631. https://doi.org/10.3390/en14123631

Academic Editors: Imre Kovách and Boldizsár Megyesi

Received: 20 April 2021

Accepted: 15 June 2021

Published: 18 June 2021

Publisher's Note: MDPI stays neutral with regard to jurisdictional claims in published maps and institutional affiliations.

Copyright: (c) 2021 by the authors. Licensee MDPI, Basel, Switzerland. This article is an open access article distributed under the terms and conditions of the Creative Commons Attribution (CC BY) license (https:/ / creativecommons.org/licenses/by/ $4.0 /)$.

\begin{abstract}
Since awareness of the influence of home energy management services (HEMS) with Internet of things (IoT) has grown, the study on the acceptance of IoT services has been expanded. Previous studies, however, have not paid attention to the acceptance itself, focusing only on factors affecting the acceptance. This study attempts to draw meaningful implications by exploring the relationships between the acceptance and the factors affecting it with distinctions between passive acceptance and active acceptance. This study analyzed the ordinal logistic regression models based on a survey of 909 adults 19 years of age and older in Korea on HEMS with IoT. In addition, we attempt the ordinal forest to increase the reliability of the research results. As a result, this study showed that consumers' perception of usefulness was noticeably important to enhance active acceptance and that those who had high sensitivity to new technology acceptance showed high active acceptance, and older women had higher active acceptance. This study might contribute to the research on IoT acceptance in the energy management sector by classifying the acceptance into active acceptance and passive acceptance beyond the framework of setting the acceptance as a single variable.
\end{abstract}

Keywords: home energy management; Internet of things; technology acceptance

\section{Introduction}

Internet of things (IoT) is a huge network comprised of physical objects and/or people connected to each other. The physical objects connected to this network collect data and exchange the data with other devices through the combination of sensing, communication, computing, and analyzing technologies [1,2].

The IoT can be effectively used for home energy management (HEM) system and is recognized as a main means of energy efficiency in general households [3,4]. The smart HEM utilizing the IoT starts with installing a system for managing a wide range of home appliances from washing machines to thermostats. More households will utilize their smartphone or web interface to manage their home appliances in the future, resulting in energy savings and an expansion of relevant markets. According to IMARC [5], the HEM market is expected to grow from USD 1.6 billion in 2018 to USD 4.4 billion in 2024. Although the development of technology is important for the smooth dissemination of innovative technologies such as the IoT, the acceptance of consumers who are to use the technology is also essential [6,7]. In particular, the key customers of home energy management services (HEMS) with IoT are the general public, so their acceptance to IoT services is directly related to success in related businesses [2,8].

Since awareness to the influence of HEMS using IoT has grown, the study on the acceptance of IoT services has been expanded. Current research on the acceptance has focused on studies of its influencing factors (e.g., perceived usefulness (PU), perceived ease of use (PEU), perceived risk (PR), and perceived enjoyment (PE)), and the negative impact of risk perception on the acceptance is a research priority [9-12]. 
The existing studies have strengthened the knowledge base for securing the acceptance of IoT services by examining the various acceptance factors of IoT services. Most of them, however, have not adopted an in-depth approach to the acceptance itself, focusing only on the factors that affect the acceptance. When accepting a certain technology or service, it can be accepted passively or actively [13]. Here, the passive acceptance indicates the mere usage of the technology or service, while the active acceptance means being willing to accept the technology or service and, at the same time, actively recommending it to others. The existing studies on the acceptance of IoT services have considered the acceptance as a single variable.

Distinguishing between active acceptance and passive acceptance helps us to understand the impact of each factor on the acceptance in more detail, which can contribute to the practicality of the strategy for enhancing the acceptance of HEMS with IoT. In particular, by identifying the factors of active acceptance, providers of HEMS with IoT can find ways to increase the voluntary efforts of users such as word of mouth. Therefore, this study attempts to analyze acceptance factors by distinguishing acceptance level into passiveness and activeness.

In addition, existing studies lacked a review of how individual propensity affects the acceptance of IoT. Macik [10] analyzed that personal innovativeness affects the intention to use IoT but did not apply economic and environmental personal propensity related to IoT in the energy management sector. In contrast, Park et al. [2] hypothesized that not only consumer innovativeness but also economic and environmental personal propensity would be significant influencing factors on risk perception for HEMS with IoT. However, Park et al. [2] focused on only risk perception rather than focusing on the overall acceptance of HEM with IoT. This study differs from Park et al. [2] by including not only risk perception but also PU, PEU, and PE as variables affecting the acceptance of HEM with IoT. This study, which deals with the effect of individual propensity on the acceptance of HEMS with IoT, will be useful in future studies of other technology acceptance factors.

In short, this study differentiated the acceptance of HEMS with IoT into passive acceptance and active acceptance and included personal propensity as an additional variable in IoT acceptance factor analysis. This approach provides a basis for a more detailed understanding of the acceptance factors of HEMS with IoT.

In Section 2, the concept of acceptance corresponding to the dependent variable is examined, being divided into passive acceptance and active acceptance, and various factors corresponding to independent variables including individual propensity are explored. Section 3 covers research models, data collection, and analysis methods. Section 4 presents the analysis results. Section 5 discusses the implications of the analysis results and Section 6 presents conclusions.

\section{Literature Review}

\subsection{Active Acceptance and Passive Acceptance}

Studies on finding the factors of technology acceptance generally set the technology acceptance as a single dependent variable and examine the magnitude of the relative influence of various independent variables on technology acceptance. All of the representative theories on technology acceptance, such as the Theory of Reasoned Action that Fishbein and Ajzen [14] introduced, Theory of Planned Behavior of Ajzen [15], and Technology Acceptance Model of Davis [6], have mainly searched for the factors affecting the behavioral intention, considering that the behavioral intention ultimately influenced the behavior.

Relatively recent studies, however, do not consider technology acceptance as a single variable of the behavioral intention, distinguishing it rather as active acceptance and passive acceptance. Wüstenhagen et al. [13] mentioned the social acceptance of renewable energy and distinguished between more active acceptance using the technology directly and passive acceptance with intention to use the technology. Sauter and Watson [16] argued that the passive acceptance of the public at the level of non-opposition to the renewable energy technology would be enough for driving large renewable energy technology projects; 
however, in terms of micro-generation technology, a more active acceptance to directly use the technology would be important. On the other hand, Yu [17] classified the behavior of using social media such as Facebook and Twitter as active use and passive use. Yu [17] regarded the behavior of simply using the information of social media as passive use and the behavior of directly producing contents as active use.

The acceptance of HEMS with IoT can also be classified into active acceptance and passive acceptance as with recent studies. The acceptance of HEMS with IoT basically assumes the use of IoT technologies. If consumers encourage others to use the services beyond passive use, this behavior can be considered to be active acceptance. In this study, active acceptance and passive acceptance are distinguished in order to judge the acceptance of IoT services in the HEM sector in detail, but they are approached rather differently from existing studies. If consumers are just willing to accept and use the technology, their behaviors are considered to be passive acceptance, and if they encourage others to use the technology, their behaviors are set to be active acceptance.

\subsection{Perception and Technology Acceptance}

The studies exploring factors influencing technology acceptance have focused on variables related to consumer perception of technology. The technology acceptance model (TAM) presented PU and PEU as key factors in accepting information system to create a positive effect on the technology acceptance of consumers. After that, studies were conducted that simply validated TAM or verified the validity of PU and PEU in the early 1990s $[18,19]$. Since the mid-1990s, many studies have been conducted to point out the limitations of TAM and to expand the TAM by supplementing those limitations.

The perceptual variables added to TAM include, but are not limited to, perceived risk (PR) and PE. PR was first introduced by Bauer [20] in the area of consumer behavior, and it is attributable to uncertainty in the purchase outcome and may be considered as loss expectancy resulting from purchase outcome [21]. In many studies based on TAM, PR has been considered as an important factor influencing acceptance and purchase intention of technologies and/or products [22,23]. The PR has become even more important in studies involving the acceptance of products and services related to technologies that were innovative, such as mobile banking, U-commerce, smart grids, and IoT, but could cause a great deal of risks to consumers [8].

PE can be defined as the degree to which the act of accepting and using the technology itself is enjoyable, regardless of the expected outcome of the technology acceptance, according to Davis et al. [24]. The PE has been addressed as an important variable influencing technology acceptance in numerous studies of extended TAM and, also, as an important variable affecting the purchase of products and services in the consumer behavior area $[25,26]$. For example, Lee et al. [26] emphasized that PE was a more influential factor than PU, which is the main component of TAM.

Recent research on the acceptance of innovative technologies such as IoT and smart grids has produced empirical findings that PU, PEU, PR, and PE affect a consumer's acceptance $[2,11,12,27,28]$. It is necessary to examine how the perceptual variables such as PU, PEU, PR, and PE, affect the acceptance of IoT services in the HEM sector and to compare their influence.

\subsection{Individual Propensity and Technology Acceptance}

Existing studies have suggested that individuals have different degrees of acceptance of new technologies depending on their characteristics [29-31]. This study tries to explore the impacts of individual propensity on acceptance of HEMS with IoT. Consumer innovativeness, which is the tendency to accept changes willingly and try new things, has been chosen as one of the main independent variables in this study. Aldás-Manzano et al. [31] explored the relationship between consumer innovativeness and risk perception in online banking, and found that the greater the consumer innovativeness was, the less the risk perception was, and the greater the intention to use was. 
Meanwhile, in research on the acceptance of energy-related technologies, the economic efficiency and eco-friendliness of the technology have been recognized as highly important values. Therefore, it is necessary to examine consumers' individual propensities related to economic and environmental factors. First, there are studies dealing with a consumer's price sensitivity or compensation sensitivity in terms of individual propensities related to economic factors. Liang et al. [32] argued that, in the case of price-competitive products, as the price sensitivity of consumers was higher, the higher perceived value and the lower PR had positive impacts on consumers' purchase intention. Reniers et al. [33] demonstrated that the higher the consumers' reward sensitivity was, the more likely they were to take risks in terms of technology and/or product acceptance.

In the case of individual propensities related to environmental factors, there have been studies exploring consumers' environmental awareness. Lima et al. [34] empirically showed that consumers' environmental awareness had an effect on product risk perception. Martínez-Peña [35] showed that the higher the environmental awareness measured with the knowledge about water resources and sewage management in a city was, the higher the risk perception for cleaning products was. Tseng et al. [36] suggested that the higher the consumers' sensitivity to electromagnetic waves was, the higher the perception of health risks to mobile phones and household appliances became. Given these studies, it can be hypothesized that the sensitivity to new technology acceptance, price sensitivity, and environmental awareness, which are consumers' individual propensities, will have a meaningful impact on the acceptance of HEMS with IoT.

\section{Methodology}

\subsection{Samples and Variables}

In order to empirically examine the determinants of the acceptance of HEMS with IoT, a survey was conducted among adults over 19 years old in Korea on HEMS with IoT in line with the time when some Korean conglomerates were promoting the commercialization of IoT smart home services in the second half of 2015. This study conducted the survey after clearly showing the effectiveness of HEMS with IoT to respondents, who were selected in an unbiased and randomized way after uniformly allocated by gender, age, and geographic region. The sampling error was $\pm 3.9 \%$ at the $95 \%$ confidence level, and the survey period was from 28 August to 2 September 2015. Hankook Research, a public opinion research firm in Korea, conducted the survey. The questionnaire consisted of four parts, consumer acceptance, consumer perception, individual propensity, and demographic variable, and each part was made up of two, four, three, and four question items, respectively (refer to Appendix A). Among them, question items in consumer acceptance and consumer perception parts have four questions. Each question's answer was made up of a sevenpoint Likert scale that ranges from strongly agree (7) to strongly disagree (1) except for age and gender. The initial sample size was 1008, but after removing the responses with missing data, the final sample size was 909.

Among the variables used in the analysis, four independent variables about consumer perception and two dependent variables about consumer acceptance were set by integrating four questions with a 7-point Likert scale through factor analysis. As a consequence of exploratory factor analysis, the Kaiser-Meyer-Olkin (KMO) value, which indicates the proportion of variance in data that could be caused by underlying factors, was more than 0.7 and the factor loading, which shows the variance explained by the variable on the particular factor, was more than 0.6. Normally, KMO values higher than 0.6 indicate that the sampling is adequate [37], and factor loadings higher than 0.6 represent that each variable is meaningful for constructing the factor [37-39]. The internal consistency of the factors was evaluated using Cronbach's alpha coefficient with the acceptable value being from 0.89 to 0.95. Additionally, we calculated composite reliability (CR) and average variance extracted (AVE) to assess the internal consistency and convergent validity, respectively, based on the results of the confirmatory factor analysis. The results showed that the values of CR and AVE were above 0.8 and 0.5 , respectively. Hence, we concluded that each question item 
could be utilized as meaningful variables, and we created the four independent variables and two dependent variables by combining each responses using mean.

Dependent variables, passive acceptance and active acceptance, were processed as ordinal variables with three levels of "low level of acceptance," "moderate level of acceptance," and "high level of acceptance". After combining responses using mean based on the results of the factor analysis, we split it into three levels, low, moderate, and high level of acceptance, with reference points of 3.5 and 4.5 , considering the balance of the sample. Further, from the individual propensity part in the questionnaire, "sensitivity to electricity price changes (StP)", "sensitivity to environmental destruction (StE)" and "sensitivity to new technology acceptance (StT)" were derived as personal characteristic variables. Demographic variables, age, gender, income level, and educational level, were also measured with and used as control variables. Table 1 shows a description of independent and dependent variables and basic information about them in a dataset.

Table 1. Descriptive statistics of variables.

\begin{tabular}{|c|c|c|c|c|c|}
\hline Variables & Description & Mean & Min. & Max. & Std. Dev. \\
\hline $\begin{array}{l}\text { Passive } \\
\text { Acceptance }\end{array}$ & $\begin{array}{c}\text { Consumers' passive acceptance of the HEMS with IoT } \\
\text { Ordinal variable } \\
0=\text { Low level of acceptance, } \\
1=\text { Moderate level of acceptance, } \\
2=\text { High level of acceptance }\end{array}$ & 1.12 & 0 & 2 & 0.85 \\
\hline $\begin{array}{c}\text { Active } \\
\text { Acceptance }\end{array}$ & $\begin{array}{c}\text { Consumers' active acceptance of the HEMS with IoT } \\
\text { Ordinal variable } \\
0=\text { Low level of acceptance, } \\
1=\text { Moderate level of acceptance, } \\
2=\text { High level of acceptance }\end{array}$ & 1.04 & 0 & 2 & 0.82 \\
\hline PU & $\begin{array}{c}\text { Consumers believe that adopting the HEMS with IoT could enhance their home energy } \\
\text { management performance. }\end{array}$ & 4.51 & 1 & 7 & 1.05 \\
\hline PEU & Consumers believe that using the HEMS with IoT is free of effort. & 4.45 & 1 & 7 & 1.13 \\
\hline PR & Risk that consumers feel when adopting the HEMS with IoT regarding the outcomes & 3.32 & 1 & 7 & 1.19 \\
\hline PE & Consumers believe that using the HEMS with IoT is personally enjoyable in its own right. & 4.35 & 1 & 7 & 1.11 \\
\hline StP & Consumers' sensitivity to changes in electricity price & 4.81 & 1 & 7 & 1.14 \\
\hline StE & Consumers are concerned about environmental destruction. & 4.88 & 1 & 7 & 1.11 \\
\hline StT & Consumers willingly embrace new technology. & 4.72 & 1 & 7 & 1.09 \\
\hline Age & Over the age of 19 & 45.14 & 19 & 92 & 14.01 \\
\hline Income & The average monthly income of households & 4.24 & 1 & 7 & 1.61 \\
\hline Education & The highest level of education they have completed & 3.84 & 2 & 7 & 1.14 \\
\hline Gender & $\begin{array}{l}\text { Dummy variable } \\
0=\text { Female, } 1 \text { = Male } \\
\text { Adapted from Park et al. [2] }\end{array}$ & 0.50 & 0 & 1 & 0.50 \\
\hline
\end{tabular}

\subsection{Research Model}

In the research model of this study, the dependent variable is consumers' acceptance of HEMS with IoT. However, differently from the previous studies, the acceptance level was subdivided into passive acceptance and active acceptance to help more specifically understand the factors influencing the acceptance of HEMS with IoT.

Independent variables include perception of HEMS with IoT and individual propensity. Perception of HEMS with IoT included PU, PEU, PR, and PE, and individual propensity included StP, StE, and StT. We hypothesized that all of these independent variables, except PR, would have a positive effect on acceptance of HEMS with IoT. On the other hand, PR would have a negative effect on acceptance of HEMS with IoT. It was assumed that the direction of independent variables affecting passive acceptance and active acceptance of HEMS with IoT will be the same (Figure 1). However, there will be differences in the extent of the impact, and we will see the differences in the results section.

This study used a total of six models composed of three models for passive acceptance and three models for active acceptance based on the ordinal logistic regression model (Figure 2). With these models, the impacts of four perceptual variables, three personal characteristic variables, and four demographic variables on the two types of acceptance were analyzed and compared. We built Model 1 and 4 as a base model, which consisted of four perceptual variables (PU, PEU, PR, and PE) and technology acceptance, and then built additional models, Models 2, 3, 5, and 6 by extending the base model to handle multi-collinearity. We added three personal characteristic variables, "StP," "StE," and "StT," 
into Model 2 and 5 to explore the influence of consumers' personal characteristic variables on the passive acceptance and active acceptance of HEMS with IoT. In Models 3 and 6, we examined additionally the effects that demographic characteristics have.

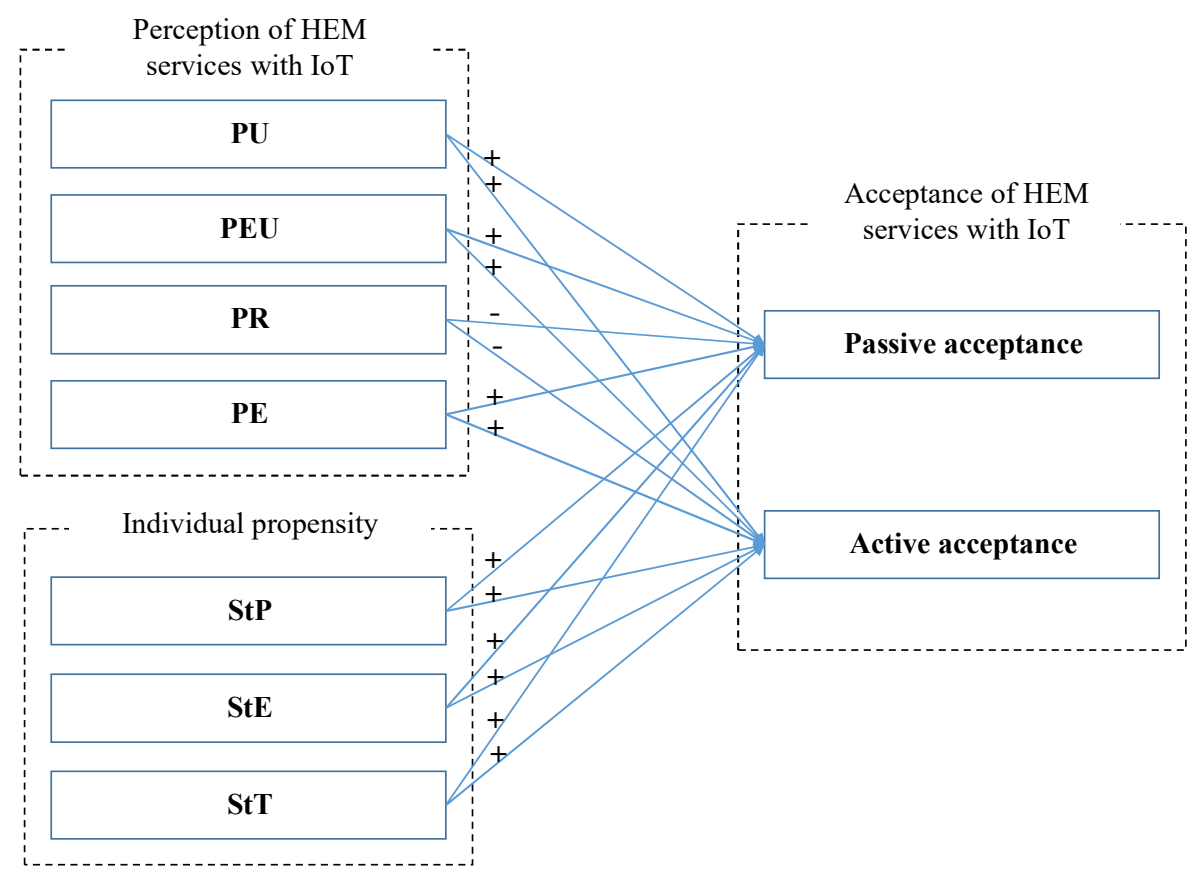

Figure 1. Basic relationship between variables.

Passive acceptance

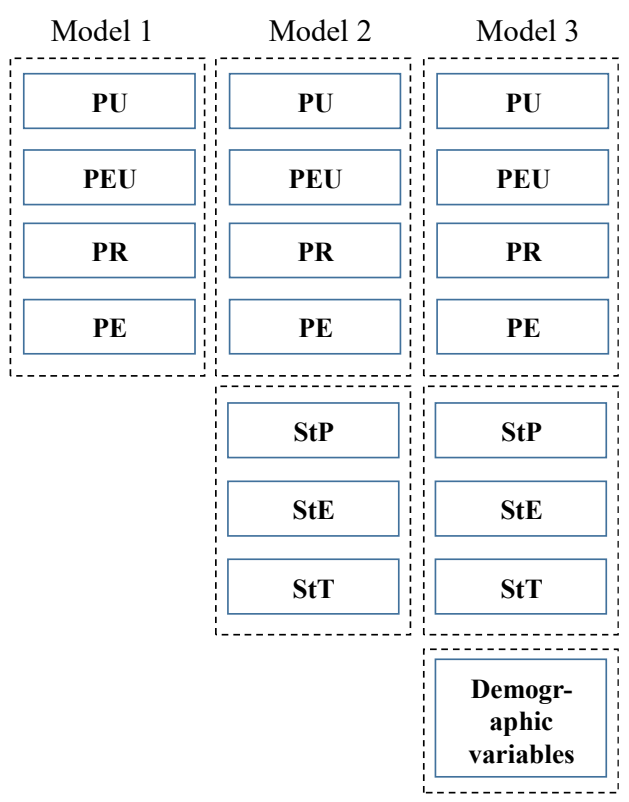

Active acceptance

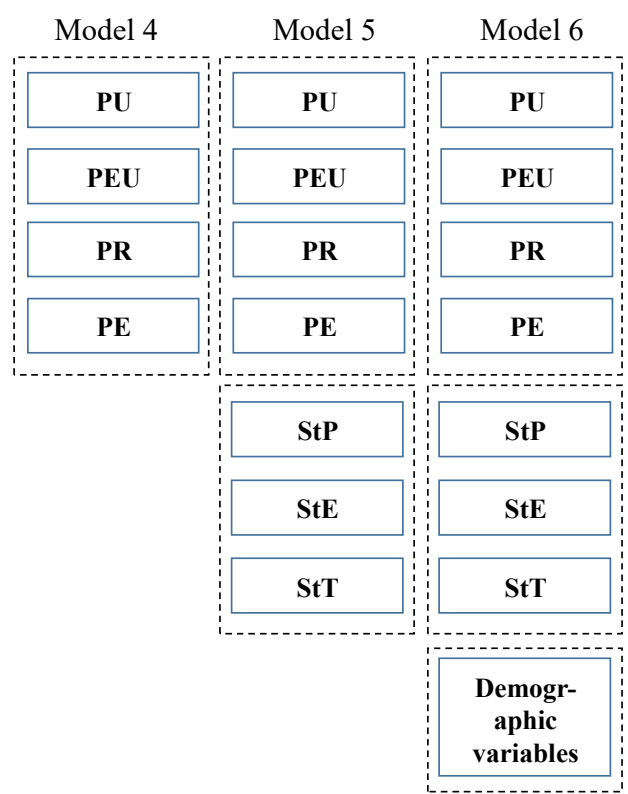

Figure 2. Research model.

\subsection{Statistical Methods}

\subsubsection{Ordinal Logistic Regression}

Since the dependent variable in this analysis has the characteristic of an ordinal variable that has three ranked categories, the ordinal logistic regression model was used [40]. The ordinal logistic regression model has been developed to examine the relationship between independent variables and a categorical and ordered dependent variable. The 
ordinal logistic regression analysis should follow not only the assumption of proportional odds but also the assumption that there should be no multi-collinearity among variables [41]. The basic expression of the ordinal logistic model is as follows:

$$
\log \left[\frac{P(y \leq j \mid x)}{1-P(y \leq j \mid x)}\right]=\mu_{j}-\sum_{k=1}^{K} \beta_{k} x_{k}
$$

The left part of the equal sign is called a logit, which is the log odds ratio, the ratio of the odds of an event occurring in a certain group to the odds of it occurring in another group. The coefficients in the logistic regression model show the changes in the logit per unit increase in an independent variable when all other independent variables are constant.

In the binary logistic regression, it is possible to derive how much odds ratio, the ratio between the probability that the dependent variable belongs to category " 0 " and " 1 ", is increased or decreased when the independent variable increases by one unit. Likewise, since the formation of the odds is cumulative in the ordinal logistic regression model, it is possible to derive how much odds ratio between the probability that the dependent variable belongs to the lower reference category and to the upper-level category in $n$ ordered categories is increased or decreased when the independent variable increases by one unit.

\subsubsection{Ordinal Forest}

In addition to the ordinal logistic regression, we attempt additional analysis to increase the reliability of the research results. Models dealing with ordinal response variables include not only the ordinal logistic regression model but also the ordinal probit regression model. The ordinal probit model relies on the error of the standard normal distribution, and the ordinal logistic model relies on the assumption that the random error follows the logistic distribution. However, it is known that there is little difference between the analysis results of these two models [42]. Therefore, it is not practical to use the ordinal probit model together with the ordinal logistic model performed in this study.

In the field of machine learning, there have been several attempts to deal with ordinal response variables, but there are few commonly used methods [43,44]. In machine learning methods, ordinal response variables are often treated as nominal variables or regression algorithms are applied [43,44]. However, the former loses the ordering information of the ordinal response variables, and the latter does not consider the fact that the extents of the classes of the ordinal variable differ from class to class [40]. Recently, Hornung [4] introduced a prediction method, which is the ordinal forest method based on the random forest, for ordinal response variables that is applicable to even high-dimensional covariate data. In the ordinal forest method, the ordinal variable is treated as a continuous variable, where the model considers the differing extents of the individual classes of the ordinal variable with the out-of-bag error estimates during the construction of the forest [4]. In this study, additional analysis is attempted by applying Hornung's [44] method optimized to deal with ordinal response variables, and the reliability of the research results is confirmed.

\section{Results}

The ordinal logistic regression analysis was performed using the MASS package in the statistical program $\mathrm{R}$, and the "zeligverse" package was additionally used to derive the marginal effect of the variables. The empirical results have been shown in Tables 2 and 3 . Prior to the ordinal logistic regression analysis, we derived variance inflation factors (VIFs) to identify the multi-collinearity between independent variables, and all variables presented the VIF values between 1 to 2 . Therefore, it can be considered that there is no multi-collinearity between independent variables [45]. To evaluate the goodness-of-fit of our logistic models, we use pseudo R-squared value, which can be interpreted as the proportion of the total variability of the outcome that is accounted for by the model. The more variability explained, the better the model. In addition, we use the deviance ( $-2 \log$ 
likelihood value), which indicates how much unexplained information there is after the model has been fitted. The higher the value, the less accurate the model.

Table 2. Results for ordered logistic model (passive acceptance).

\begin{tabular}{|c|c|c|c|c|c|c|}
\hline \multirow{3}{*}{ Variables } & \multicolumn{6}{|c|}{ Passive Acceptance $^{1}$} \\
\hline & \multicolumn{2}{|c|}{ Model 1} & \multicolumn{2}{|c|}{ Model 2} & \multicolumn{2}{|c|}{ Model 3} \\
\hline & $\beta$ & $\operatorname{Exp}(\beta)$ & $\beta$ & $\operatorname{Exp}(\beta)$ & $\beta$ & $\operatorname{Exp}(\beta)$ \\
\hline PU & $\begin{array}{l}0.531^{* * *} \\
(0.107)\end{array}$ & 1.700 & $\begin{array}{l}0.464^{* * *} \\
(0.109)\end{array}$ & 1.590 & $\begin{array}{c}0.458^{* * *} \\
(0.109)\end{array}$ & 1.582 \\
\hline PEU & $\begin{array}{l}0.455^{* * *} \\
(0.087)\end{array}$ & 1.576 & $\begin{array}{l}0.412^{* * *} \\
(0.089)\end{array}$ & 1.510 & $\begin{array}{l}0.410^{* * *} \\
(0.090)\end{array}$ & 1.506 \\
\hline PR & $\begin{array}{l}-0.658^{* * *} \\
(0.088)\end{array}$ & 0.518 & $\begin{array}{l}-0.654^{* * *} \\
(0.089)\end{array}$ & 0.520 & $\begin{array}{l}-0.653^{* * *} \\
(0.090)\end{array}$ & 0.521 \\
\hline $\mathrm{PE}$ & $\begin{array}{l}0.431^{* * *} \\
(0.080)\end{array}$ & 1.539 & $\begin{array}{l}0.322 * * * \\
(0.084)\end{array}$ & 1.380 & $\begin{array}{l}0.324^{* * *} \\
(0.084)\end{array}$ & 1.383 \\
\hline StP & & & $\begin{array}{l}0.125^{*} \\
(0.072)\end{array}$ & 1.133 & $\begin{array}{l}0.123^{*} \\
(0.073)\end{array}$ & 1.131 \\
\hline StE & & & $\begin{array}{l}-0.048 \\
(0.081)\end{array}$ & 0.953 & $\begin{array}{l}-0.061 \\
(0.083)\end{array}$ & 0.941 \\
\hline StT & & & $\begin{array}{l}0.383^{* * *} \\
(0.084)\end{array}$ & 1.466 & $\begin{array}{l}0.399 * * * \\
(0.087)\end{array}$ & 1.490 \\
\hline Age & & & & & $\begin{array}{c}0.047 \\
(0.053)\end{array}$ & 1.048 \\
\hline Income & & & & & $\begin{array}{c}0.056 \\
(0.046)\end{array}$ & 1.057 \\
\hline Education & & & & & $\begin{array}{c}-0.084 \\
(0.068)\end{array}$ & 0.920 \\
\hline $\begin{array}{c}\text { Gender } \\
\text { (Male compared to female) }\end{array}$ & & & & & $\begin{array}{l}-0.025 \\
(0.152)\end{array}$ & 0.976 \\
\hline Number of cases & \multicolumn{2}{|c|}{909} & \multicolumn{2}{|c|}{909} & \multicolumn{2}{|c|}{909} \\
\hline-2 log likelihood & \multicolumn{2}{|c|}{1414.8} & \multicolumn{2}{|c|}{1432.3} & \multicolumn{2}{|c|}{1457.9} \\
\hline $\begin{array}{l}\text { Pseudo R2 } \\
\text { (Nagelkerke) }\end{array}$ & \multicolumn{2}{|c|}{0.460} & \multicolumn{2}{|c|}{0.481} & \multicolumn{2}{|c|}{0.483} \\
\hline
\end{tabular}

$1 *$ Significance level: $0.1{ }^{* * *}$ significance level: 0.01 .

Table 3. Results for ordered logistic model (active acceptance).

\begin{tabular}{|c|c|c|c|c|c|c|}
\hline \multirow{3}{*}{ Variables } & \multicolumn{6}{|c|}{ Active Acceptance $^{1}$} \\
\hline & \multicolumn{2}{|c|}{ Model 4} & \multicolumn{2}{|c|}{ Model 5} & \multicolumn{2}{|c|}{ Model 6} \\
\hline & $\beta$ & $\operatorname{Exp}(\beta)$ & $\beta$ & $\operatorname{Exp}(\beta)$ & $\beta$ & $\operatorname{Exp}(\beta)$ \\
\hline PU & $\begin{array}{l}1.002 * * * \\
(0.111)\end{array}$ & 2.723 & $\begin{array}{l}0.958^{* * *} \\
(0.112)\end{array}$ & 2.606 & $\begin{array}{l}0.955^{* * *} \\
(0.115)\end{array}$ & 2.600 \\
\hline PEU & $\begin{array}{l}0.396^{* * *} \\
(0.086)\end{array}$ & 1.486 & $\begin{array}{c}0.364^{* * *} \\
(0.087)\end{array}$ & 1.439 & $\begin{array}{l}0.357^{* * *} \\
(0.088)\end{array}$ & 1.428 \\
\hline PR & $\begin{array}{l}-0.526^{* * *} \\
(0.087)\end{array}$ & 0.591 & $\begin{array}{c}-0.525^{* * *} \\
(0.088)\end{array}$ & 0.592 & $\begin{array}{l}-0.570^{* * *} \\
(0.090)\end{array}$ & 0.566 \\
\hline PE & $\begin{array}{l}0.296^{* * *} \\
(0.081)\end{array}$ & 1.345 & $\begin{array}{l}0.224^{* * *} \\
(0.086)\end{array}$ & 1.252 & $\begin{array}{l}0.235^{* * *} \\
(0.087)\end{array}$ & 1.265 \\
\hline StP & & & $\begin{array}{l}-0.031 \\
(0.073)\end{array}$ & 0.969 & $\begin{array}{l}-0.085 \\
(0.075)\end{array}$ & 0.919 \\
\hline StE & & & $\begin{array}{c}0.102 \\
(0.080)\end{array}$ & 1.108 & $\begin{array}{c}0.020 \\
(0.084)\end{array}$ & 1.020 \\
\hline StT & & & $\begin{array}{l}0.227^{* * *} \\
(0.086)\end{array}$ & 1.255 & $\begin{array}{l}0.334^{* * *} \\
(0.089)\end{array}$ & 1.396 \\
\hline Age & & & & & $\begin{array}{l}0.128 * * \\
(0.053)\end{array}$ & 1.136 \\
\hline Income & & & & & $\begin{array}{c}0.063 \\
(0.048)\end{array}$ & 1.065 \\
\hline Education & & & & & $\begin{array}{l}-0.085 \\
(0.067)\end{array}$ & 0.918 \\
\hline $\begin{array}{c}\text { Gender } \\
\text { (Male compared to female) }\end{array}$ & & & & & $\begin{array}{l}-0.629^{* * *} \\
(0.157)\end{array}$ & 0.533 \\
\hline Number of cases & \multirow{2}{*}{\multicolumn{2}{|c|}{$\begin{array}{c}909 \\
1381.1\end{array}$}} & \multirow{2}{*}{\multicolumn{2}{|c|}{$\begin{array}{c}909 \\
1415.0\end{array}$}} & \multicolumn{2}{|c|}{909} \\
\hline-2 log likelihood & & & & & \multicolumn{2}{|c|}{1406.9} \\
\hline $\begin{array}{l}\text { Pseudo R } \\
\text { (Nagelkerke) }\end{array}$ & \multicolumn{2}{|c|}{0.510} & \multicolumn{2}{|c|}{0.519} & \multicolumn{2}{|c|}{0.536} \\
\hline
\end{tabular}

${ }^{1}$ Significance level: $0.1,^{* *}$ significance level: $0.05,{ }^{* * *}$ significance level: 0.01 .

Model 5 was designed by adding individual propensity variables to Model 4, and the analysis showed that one variable of them was significant, even though the deviance of the model increased. Model 6 was designed by adding demographic variables to Model 5, and the analysis showed that one of individual propensity variables was still significant and two of the demographic variables were significant, and even the deviance of the model was 
lowered. Therefore, we concluded that Model 6 is the optimal model that can represent the significance of demographic variables. Along the same lines, Model 2 was designed by adding individual propensity variables to Model 1, and the analysis showed that two variables of them were significant, even though the deviance of the model increased. Model 3 was designed by adding demographic variables to Model 2, and the analysis showed that two individual propensity variables were still significant, but the demographic variables were not. We however interpret the results based on the Model 3 and Model 6 to compare them at the same level.

First, in the examination of the impact of perceptual variables on passive acceptance, all four variables of PU, PEU, PR, and PE had statistically significant influence at $1 \%$ level. The exponential beta values of PU, PEU, and PE were 1.582, 1.506, and 1.383, respectively. This can be interpreted that single unit increase in each PU, PEU, and PE is linked to an increase of the probability of passive acceptance from reference category (low level of acceptance) to upper-level category (from moderate level of acceptance to high level of acceptance) by $58.2 \%, 50.6 \%$, and $38.3 \%$, respectively. In other words, the higher the PU, PEU, and PE of HEMS with IoT are, the greater the passive acceptance of the services is. The exponential beta value of the PR was 0.521 , and this can be interpreted that single unit increase in PR is linked to a decrease of the probability of passive acceptance from reference category to upper-level category by $47.9 \%$. This means that the higher the PR of HEMS with IoT is the lower the passive acceptance of the services is.

Likewise, in the case of active acceptance, all four variables of PU, PEU, PR, and PE had statistically significant influence at $1 \%$ level. The exponential beta values of PU, PEU, and PE were $2.600,1.428$, and 1.265 , respectively. It can be interpreted that single unit increase in each PU, PEU, and PE is related with an increase of the probability of passive acceptance from reference category to upper-level category by $160.0 \%, 42.8 \%$, and $26.5 \%$, respectively. The exponential beta value of PR was 0.566 , and this can be interpreted that single unit increase in PR is related with a decrease of the probability of passive acceptance from reference category to upper-level category by $43.4 \%$.

Regarding the impact of individual propensities on the passive acceptance, the StP and the StT were statistically significant at 10\% level and 1\% level, respectively, while the StE was not statistically significant. The exponential beta values of the StP and StT were 1.131 and 1.490, respectively, and this can be interpreted that single unit increase in each StP, and StT is related with an increase of the probability of passive acceptance from reference category to upper-level category by $13.1 \%$ and $49.0 \%$, respectively. In the case of the active acceptance, the StP was not affected significantly, whereas the StT was statistically significant at a $1 \%$ level.

When additionally examining the relationship with demographic variables, there was no significant impact of the four perceptual variables on the passive acceptance. In the case of the active acceptance, age and gender had statistically significant impacts at $5 \%$ and $1 \%$ level, respectively. The exponential beta values of age and gender were 1.136 and 0.533 , respectively. This means that the older ages have higher active acceptance for HEMS, and women have higher active acceptance for the services in comparison to men.

Tables 4 and 5 present the marginal effects, which measure the impact of an instantaneous unit shift in a certain independent variable on the dependent variable while keeping all the other variables constant. When examining the relationship between PU and passive acceptance, it can be seen that for every one-unit increase in PU, the probability of selecting a "low level of acceptance" decreases by $47.27 \%$, the probability of selecting a "moderate level of acceptance" increases by $5.26 \%$, and the probability of selecting a "high level of acceptance" increases by $42.01 \%$. When examining the relationship between PU and active acceptance, it can be seen that for every one-unit increase in PU, the probability of selecting a "low level of acceptance" decreases by $85.00 \%$, the probability of selecting a "moderate level of acceptance" increases by $23.66 \%$, and the probability of selecting a "high level of acceptance" increases by $61.34 \%$. In other words, active acceptance is more sensitive to changes in PU than passive acceptance. 
Table 4. Marginal effects (passive acceptance).

\begin{tabular}{cccc}
\hline Passive Acceptance & $\begin{array}{c}\text { Low Level of } \\
\text { Acceptance }\end{array}$ & $\begin{array}{c}\text { Moderate Level of } \\
\text { Acceptance }\end{array}$ & $\begin{array}{c}\text { High Level of } \\
\text { Acceptance }\end{array}$ \\
\hline PU & -0.4727 & 0.0526 & 0.4201 \\
PEU & -0.4244 & 0.0486 & 0.3758 \\
PR & 0.6752 & -0.1205 & -0.5547 \\
PE & -0.3335 & 0.0104 & 0.3232 \\
StP & -0.1266 & 0.0090 & 0.1176 \\
StE & 0.0505 & 0.0113 & -0.0618 \\
StT & -0.4269 & 0.0547 & 0.3722 \\
Age & -0.0521 & -0.0038 & 0.0559 \\
Income & -0.0535 & -0.0033 & 0.0568 \\
Education & 0.0814 & 0.0079 & -0.0893 \\
Gender & 0.0044 & 0.0018 & -0.0062 \\
\hline
\end{tabular}

Table 5. Marginal effects (active acceptance).

\begin{tabular}{cccc}
\hline Active Acceptance & $\begin{array}{c}\text { Low Level of } \\
\text { Acceptance }\end{array}$ & $\begin{array}{c}\text { Moderate Level of } \\
\text { Acceptance }\end{array}$ & $\begin{array}{c}\text { High Level of } \\
\text { Acceptance }\end{array}$ \\
\hline PU & -0.8500 & 0.2366 & 0.6134 \\
PEU & -0.3680 & 0.0813 & 0.2867 \\
PR & 0.6052 & -0.1453 & -0.4599 \\
PE & -0.2418 & 0.0383 & 0.2035 \\
StP & 0.0793 & 0.0081 & -0.0874 \\
StE & -0.0229 & 0.0052 & 0.0177 \\
StT & -0.3606 & 0.0967 & 0.2639 \\
Age & -0.1359 & -0.0019 & 0.1379 \\
Income & -0.0595 & 0.0050 & 0.0544 \\
Education & 0.0831 & -0.0011 & -0.0820 \\
Gender & 0.1016 & -0.0052 & -0.0964 \\
\hline
\end{tabular}

We also examined the reliability of the results of the ordinal logistic regression analysis by using the ordinal forest (Table 6). The ordinal forest predicts the values of an ordinal target variable for new observations based on covariate values, and it ranks the importance of the covariates regarding predicting the values of the ordinal target variable [44]. We used the default values for several hyperparamers such as the number of score sets, trees, permutations of the class width, and so on. Hornung [44] insists that those default values were found to be in a reasonable range in his study, and they are not necessary to change these values in most cases. We used the ordinalForest v2.4-1 (Munich, Germany) which is the newest version and programmed with $R$.

We extracted the importance of variables for the perception of HEM with IoT and the individual propensity which were key variables in this study. The importance is extracted based on permutation. In other words, after getting a trained model, the order of the data of a variable is randomly shuffled, and then, the accuracy is checked to know the importance of the variable. In addition, it is examined how different the accuracy is from the result of the trained model. The same process is repeated for another variable again. The higher the importance value derived in this way, the more important the variable is. As a result of the analysis, for passive acceptance, the rest showed the same results, except that the rankings of PEU and StT were changed. For active acceptance, the remaining results were the same, except that the rankings of PE and StT changed. In general, there were some differences in the middle ranking, but the results of the logistic regression model and the ordinal forest model were similar. In particular, variables with high influence showed the same results in both models. 
Table 6. Variable importance derived from the ordinal forest.

\begin{tabular}{|c|c|c|c|c|c|c|}
\hline \multirow[b]{3}{*}{$\begin{array}{l}\text { Independent } \\
\text { Variables }\end{array}$} & \multicolumn{6}{|c|}{ Dependent Variables } \\
\hline & \multicolumn{3}{|c|}{ Passive Acceptance } & \multicolumn{3}{|c|}{ Active Acceptance } \\
\hline & $\begin{array}{c}\text { Importance } \\
\text { (From the } \\
\text { Ordinal } \\
\text { Forest) }\end{array}$ & $\begin{array}{c}\text { Rank } \\
\text { (From the } \\
\text { Ordinal Forest) }\end{array}$ & $\begin{array}{c}\text { Rank } \\
\text { (From the } \\
\text { Logistic } \\
\text { Regression) }\end{array}$ & $\begin{array}{l}\text { Importance } \\
\text { (From the } \\
\text { Ordinal } \\
\text { Forest) }\end{array}$ & $\begin{array}{c}\text { Rank } \\
\text { (From the } \\
\text { Ordinal } \\
\text { Forest) }\end{array}$ & $\begin{array}{c}\text { Rank } \\
\text { (From the } \\
\text { Logistic } \\
\text { Regression) }\end{array}$ \\
\hline PU & 0.04149 & 2 & 2 & 0.09861 & 1 & 1 \\
\hline PEU & 0.03490 & 4 & 3 & 0.03165 & 3 & 3 \\
\hline PR & 0.07655 & 1 & 1 & 0.05492 & 2 & 2 \\
\hline PE & 0.03065 & 5 & 5 & 0.02327 & 4 & 5 \\
\hline StP & 0.00804 & 6 & 6 & -0.00153 & 7 & 7 \\
\hline StE & 0.00433 & 7 & 7 & -0.00120 & 6 & 6 \\
\hline StT & 0.03973 & 3 & 4 & 0.01361 & 5 & 4 \\
\hline
\end{tabular}

\section{Discussion}

\subsection{Theoretical Discussion}

This study has a theoretical contribution in that it examined factors affecting consumers' acceptance of HEM services with IoT, putting the consumers' acceptance in a different way from the existing studies by classifying the acceptance into passive acceptance and active acceptance. The passive acceptance means the acceptance at the level of just using the technology, and the active acceptance indicates the acceptance at the level of encouraging others to use the technology beyond their own use of the technology.

In this study, the dependent variable, technology acceptance, was divided into active acceptance and passive acceptance, so that the influence of various acceptance factors, which are independent variables, could be viewed in more detail. The subdivision of technology acceptance itself needs further research in the future. Beyond this study that separates technology acceptance into active acceptance and passive acceptance, studies from different angles such as the continuance of acceptance and the speed of acceptance can proceed. Continuance of acceptance is how long a consumer will accept a technology if they accept it, and the speed of acceptance is an indicator of how quickly they accept the technology. Regarding continuance of acceptance, Bhattacherjee's [46] Expectation Confirmation Model (ECM) is a representative example. The study presented the ECM by combining TAM and Oliver's [47] Expectation Disconfirmation Theory (EDT) to effectively explain the continuance of use. However, the study only looked at the factors influencing continuous use and did not approach in detail how long it would last. Therefore, it is necessary to carry out research on technology acceptance to classify the degree of continuous use. If the speed of acceptance is also reviewed separately by stages, acceptance factors can be interpreted in a multifaceted way.

Among the three variables about individual propensity, only StE were not found to increase passive acceptance. The reason why StE did not affect passive acceptance statistically requires more detailed examination. Environmental factors are essential in the acceptance of energy technologies. Eco-friendly energy technologies have significant impacts on consumers' perception of usefulness and ultimately enhance the acceptance of the technologies [10]. In this study, therefore, we hypothesized that those who are more sensitive to environmental destruction would accept the HEMS with IoT better because the services might contribute to environmental protection by inducing efficient energy use. However, the results showed that the hypothesis was not statistically significant. These results suggest that those responding to the survey may have the perception that the contribution of HEMS with IoT is not so high in environmental aspects. Otherwise, there might be a lack of awareness how the services will contribute to the environment. It is considered that the effect of HEMS with IoT is only promoted in terms of saving electricity costs without special mention about the contribution in environmental aspects [48]. 


\subsection{Empirical Discussion}

As shown in the results, the directions of relationships between the factors and the passive acceptance and of relationships between the factors and the active acceptance have similarities, but we could find significant differences in detail.

First, four perceptual factors, PU, PEU, PR, and PE, were statistically significant at the $1 \%$ level in the relationships with both passive acceptance and active acceptance. However, there was a more significant increase in active acceptance than in passive acceptance when the PU of the HEMS was higher, considering each PU's exponential beta values. In other words, $\mathrm{PU}$ of technology is a significant influence factor on the passive acceptance of the technology, but it becomes a stronger influence factor on active acceptance. This result suggests that if the use of a technology is recommended to others, then the PU of the technology should be prioritized.

PR is the most influential variable in passive acceptance but changes to second place in active acceptance. Reducing the risk perception for a technology is a very important task, especially given the strong impact of risk perception on technology in passive acceptance. Park et al. [2] emphasized the need for transparent information provision by service providers and reasonable standards or guidelines from regulatory agencies to reduce risk perception of HEMS with IoT. They emphasized that it is necessary to allow consumers to confirm that the equipment used for the IoT services meets the appropriate electromagnetic radiation standards. Park et al. [8] also pointed out policy tasks to lessen the risk perception in a study of the acceptance of smart grids. They suggested that governments strengthen the standard for smart grid privacy and cybersecurity. The rules regarding the ownership of consumer data, access limitations, and data use permissions should be provided.

Among the variables related to perception of technology, PEU has a high influence after PU and PR. PEU is a key variable affecting the acceptance of HEMS with IoT, regardless of passive and active acceptance. Accordingly, providers need to consider compatibility with existing products and services when developing services, and they need to develop additional means for consumers to easily understand the services [10]. PE also has a similar level of importance to PEU. In order to increase the acceptance of HEMS with IoT, measures are required so that consumers can enjoy the services. For example, it is possible to provide HEMS with IoT in a game-like form or develop an on-line character that responds pleasantly to consumers' energy saving behavior.

Secondly, in the view of active acceptance, only StT among variables about consumers propensities was a significant factor. It is also commonly emphasized in the previous studies that innovators and early adopters with high StT are more likely to accept the technology than those with low StT and are also more likely to recommend the use of the technology to others [45]. In this study, the influence of the StT on active acceptance was somewhat relatively higher than that on passive acceptance. Meanwhile, the positive relationship between StP and active acceptance is not statistically significant, while the positive relationship between StP and passive acceptance is statistically significant. In other words, just because consumers are sensitive the electricity price changes, it cannot be said that such tendency affects even the active acceptance to the extent of recommending the HEMS to others.

Thirdly, age and gender were found to be statistically significant in relationships with active acceptance among demographic variables. All the demographic variables (age, income, education, and gender) selected in this study, however, were not statistically significant in relationships with passive acceptance. Older people showed higher active acceptance, but the impact of age on the active acceptance was not so high. Nevertheless, it is noteworthy that older people preferred to recommend the use of IoT technologies to others. However, there are few studies on the difference between passive acceptance and active acceptance according to age. According to related studies, there is a claim that information acquisition through word of mouth is more general than via Internet as age increases [49], while there is another claim that older people have more conservative tendency with knowledge accumulation, so their word-of-mouth influence reduces [50,51]. 
This study shows that the tendency to actively encourage the use of HEM services with IoT is more statistically significant as age increases. It is difficult to say with certainty that older people have a stronger tendency to encourage new products and services to others. However, it is worthy to refer to this as a result of an empirical study when carrying out related studies in the future.

There have been many studies on the relationship between gender and technology acceptance. In particular, it is generally accepted that males are more active than females in accepting new technologies [52,53]. However, there are few studies on the difference between passive acceptance and active acceptance according to gender. This study showed that the impact of gender on passive acceptance is not statistically significant, but in terms of active acceptance, women are more likely to encourage actively others to use the new services. The results are consistent with results from previous research such as Bae and Lee [54] and Venkatesh et al. [55].

\section{Conclusions}

Based on this study, the statistically significant factors influencing the passive and active acceptance of the HEMS with IoT were examined, and the differences in influence between the factors could be identified. In particular, this study showed that recognition and evaluation of the services were generally important, and especially, PU was noticeably important to enhance active acceptance. In addition, those who had higher sensitivity to new technology acceptance, those who were older, and those who were women tend to have higher active acceptance. To sum up these results, in order to increase active acceptance beyond passive acceptance, raising positive recognition of the HEMS with IoT is a priority, and marketing to consumers who have high sensitivity to new technology acceptance, to older consumers, and to female consumers could make the spread of the services accelerated.

This study contributes to research on IoT acceptance in the energy management sector by classifying the acceptance into active acceptance and passive acceptance beyond the framework of setting the acceptance as a single variable, which was presented by the existing studies, and by identifying how consumers' perception, individual propensity, and demographic characteristics affect the acceptance of HEMS with IoT.

This study also has some limitations that need to be overcome in that the interaction effect between variables was not seen and the sub-influencing factors of the main influencing factors were not additionally looked at. To develop this study, it is necessary to further confirm the interaction effect between various variables. The acceptance factors can be understood in further detail when the interaction between two or more variables, as well as the independent effects of individual variables, is examined. In particular, we will be able to reach more detailed conclusions if we examine how individual propensity and demographic characteristics are connected to consumers' perception and how individual propensity and demographic characteristics are connected to each other. In addition, among consumers' perception factors, PU has a strong influence on the acceptance of technology, so it is necessary to check the PU in more detail. The perception of usefulness can be further subdivided into economic performance, environmental performance, and stability in the use of electricity. The contents of the survey used in this study are limited in that its design was not subdivided to explore the perception of usefulness in detail. More in-depth survey design is required to examine the perception of usefulness in future research.

Author Contributions: C.P. and M.J. developed the framework of this study. They discussed and co-wrote the article. All authors have read and agreed to the published version of the manuscript.

Funding: This research received no external funding.

Institutional Review Board Statement: Not applicable.

Informed Consent Statement: Not applicable. 
Data Availability Statement: Data were obtained from Korea Energy Economics Institute and are available with the permission of Korea Energy Economics Institute.

Acknowledgments: The data used in this study were based on the results of a survey conducted by Korea Energy Economics Institute in 2015.

Conflicts of Interest: The authors declare no conflict of interest.

\section{Appendix A. Question Wording}

\section{Consumer acceptance}

"Please indicate how much you agree with each of the following statements, or how true it is about you." (Response format: $1=$ Strongly disagree; $2=$ Disagree; $3=$ Somewhat disagree; $4=$ Neither agree nor disagree; $5=$ Somewhat agree; $6=$ Agree; $7=$ Strongly agree)

Passive acceptance

1. "I will use the IoT-based home energy management services in the future."

2. "I am not reluctant to use the IoT-based home energy management services."

3. "I am confident that I can utilize the IoT-based home energy management services."

4. "I will sign up for the IoT-based home energy management services."

\section{Active acceptance}

1. "I would say to others that the IoT-based home energy management services are favorable."

2. "I would encourage others to use the IoT-based home energy management services."

3. "I will not follow an opinion against the IoT-based home energy management services."

4. "I will use my influence to make my friends use the IoT-based home energy management services."

\section{Consumer perception}

"Please indicate how much you agree with each of the following statements, or how true it is about you." (Response format: $1=$ Strongly disagree; $2=$ Disagree; $3=$ Somewhat disagree; $4=$ Neither agree or disagree; $5=$ Somewhat agree; $6=$ Agree; $7=$ Strongly agree) Perceived usefulness

1. "There is more to gain than to lose from the IoT-based home energy management services."

2. "The IoT-based home energy management services offer significant advantages compared to other services."

3. "Using the IoT-based home energy management services improves my energy management capabilities."

4. "The IoT-based home energy management services are useful for energy management."

Perceived ease-of-use

1. "The IoT-based home energy management services are not difficult to use."

2. "Using the IoT-based home energy management services is not complicated."

3. "The procedure for using the IoT-based home energy management services is clear."

4. " "Using the IoT-based home energy management services is convenient."

Perceived risk

1. "I am afraid to use the IoT-based home energy management services."

2. "Using the IoT-based home energy management services is dangerous."

3. "Using the IoT-based home energy management services makes me nervous."

4. " "Using the IoT-based home energy management services can be harmful." 


\section{Perceived enjoyment}

1. "I think it would be fun to directly control IoT devices for efficient energy management."

2. "The IoT-based home energy management services excite my curiosity."

3. "I am pleased to be able to check my energy information in detail through the IoTbased home energy management services."

4. "I will enjoy managing energy systems in real time through the IoT-based services."

\section{Individual propensity}

"Please indicate how much you agree with each of the following statements, or how true it is about you." (Response format: $1=$ Strongly disagree; $2=$ Disagree; $3=$ Somewhat disagree; $4=$ Neither agree nor disagree; $5=$ Somewhat agree; $6=$ Agree; $7=$ Strongly agree)

Sensitivity to electricity price changes

"I am sensitive to changes in electricity rates."

Sensitivity to environmental destruction

"I am concerned about global environmental destruction."

Sensitivity to new technology acceptance

"I am active in accepting new technologies."

4. Demographic variable

Age

"How old are you this year?"

Income

"Which of the following is the average monthly income of your household?" (Response format: $1=$ Less than 1,000,000 Won; $2=1,000,000-2,000,000$ Won; $3=2,000,000$ $3,000,000$ Won; $4=3,000,000-4,000,000$ Won; $5=4,000,000-5,000,000$ Won; $6=5,000,000$ $6,000,000$ Won; $7=$ More than 6,000,000 Won)

\section{Education}

"Which of the following is the highest level of education you have completed?" (Response format: 1 = Elementary School; 2 = Middle School; 3 = High School; 4 = 2-year College; 5 = Bachelor's Degree; $6=$ Master's Degree; $7=$ Doctoral Degree)

Gender

"What is your gender?" (Response format: 1 = Male; 2 = Female)

\section{References}

1. Industrial Internet Consortium. Industrial Internet Reference Architecture. Technical Article. Available online: http://www. iiconsortium.org/IIRA.htm (accessed on 6 May 2015).

2. Park, C.; Kim, Y.; Jeong, M. Influencing factors on risk perception of IoT-based home energy management services. Telemat. Inform. 2018, 35, 2355-2365. [CrossRef]

3. Mahapatra, C.; Moharana, A.; Leung, V. Energy management in smart cities based on Internet of Things: Peak demand reduction and energy savings. Sensors 2017, 17, 2812. [CrossRef]

4. Tushar, W.; Wijerathne, N.; Li, W.T.; Yuen, C.; Poor, H.V.; Saha, T.K.; Wood, K.L. IoT for green building management. arXiv 2018, arXiv:1805.10635.

5. IMARC. Home Energy Management Systems Market: Global Industry Trends, Share, Size, Growth, Opportunity and Forecast 2019-2024; IMARC: Arlington, VA, USA, 2019.

6. Davis, F.D. Perceived usefulness, perceived ease of use, and user acceptance of information technology. MIS Q. 1989, 13, 319-340. [CrossRef]

7. Ram, S.; Sheth, J.N. Consumer resistance to innovations: The marketing problem and its solutions. J. Consum. Mark. 1989, 6, 5-14. [CrossRef]

8. Park, C.K.; Kim, H.J.; Kim, Y.S. A study of factors enhancing smart grid consumer engagement. Energy Policy 2014, 72, 211-218. [CrossRef]

9. Park, E.; Cho, Y.; Han, J.; Kwon, S.J. Comprehensive approaches to user acceptance of Internet of Things in a smart home environment. IEEE Internet Things J. 2017, 4, 2342-2350. [CrossRef]

10. Macik, R. The adoption of the internet of things by young consumers-an empirical investigation. Econ. Environ. Stud. 2017, 17, 363-388. [CrossRef] 
11. Kowatsch, T.; Maass, W. Critical Privacy factors of Internet of Things Services: An Empirical Investigation with Domain Experts. In Mediterranean Conference on Information Systems; Springer: Berlin/Heidelberg, Germany, 2012; pp. $200-211$.

12. Hsu, C.L.; Lin, J.C.C. An empirical examination of consumer adoption of Internet of Things services: Network externalities and concern for information privacy perspectives. Comput. Hum. Behav. 2016, 62, 516-527. [CrossRef]

13. Wüstenhagen, R.; Wolsink, M.; Bürer, M.J. Social acceptance of renewable energy innovation: An introduction to the concept Energy Policy 2007, 35, 2683-2691. [CrossRef]

14. Fishbein, M.; Ajzen, I. Belief, attitude, intention, and behavior: An introduction to theory and research. J. Bus. Ventur. 1977, 5, 177-189.

15. Ajzen, I. From intentions to actions: A theory of planned behavior. In Action Control; Springer: Berlin/Heidelberg, Germany, 1985; pp. 11-39.

16. Sauter, R.; Watson, J. Strategies for the deployment of micro-generation: Implications for social acceptance. Energy Policy 2007, 35, 2770-2779. [CrossRef]

17. Yu, R.P. The relationship between passive and active non-political social media use and political expression on Facebook and Twitter. Comput. Hum. Behav. 2016, 58, 413-420. [CrossRef]

18. Adams, D.A.; Nelson, R.R.; Todd, P.A. Perceived usefulness, ease of use, and usage of information technology: A replication. MIS Q. 1992, 16, 227-247. [CrossRef]

19. Sengars, A.; Grover, V. Re-Examining Perceived Ease of Use and Usefulness: A Confirmatory Factor Analysis. Manag. Inf. Syst. Q. $1993,17,7$

20. Bauer, R.A. Consumer Behavior as Risk Taking; American Marketing Association: Chicago, IL, USA, 1960; pp. 384-398.

21. Cox, D.F. Risk handling in consumer behavior: An intensive study of two cases. In Risk Taking and Information Handling in Consumer Behavior; Division of Research, Graduate School of Business Administration, Harvard University: Cambridge, MA, USA, 1967; pp. 34-81.

22. Park, J.; Lee, D.; Ahn, J. Risk-focused e-commerce adoption model: A cross-country study. J. Glob. Inf. Technol. Manag. 2004, 7, 6-30. [CrossRef]

23. Chen, C.F.; Xu, X.; Arpan, L. Between the technology acceptance model and sustainable energy technology acceptance model: Investigating smart meter acceptance in the United States. Energy Res. Soc. Sci. 2017, 25, 93-104. [CrossRef]

24. Davis, F.D.; Bagozzi, R.P.; Warshaw, P.R. Extrinsic and intrinsic motivation to use computers in the workplace 1. J. Appl. Soc. Psychol. 1992, 22, 1111-1132. [CrossRef]

25. Padilla-MeléNdez, A.; Del Aguila-Obra, A.R.; Garrido-Moreno, A. Perceived playfulness, gender differences and technology acceptance model in a blended learning scenario. Comput. Educ. 2013, 63, 306-317. [CrossRef]

26. Lee, J.; Kim, J.; Choi, J.Y. The adoption of virtual reality devices: The technology acceptance model integrating enjoyment, social interaction, and strength of the social ties. Telemat. Inform. 2019, 39, 37-48. [CrossRef]

27. Gao, L.; Bai, X. A unified perspective on the factors influencing consumer acceptance of internet of things technology. Asia Pac. J. Mark. Logist. 2014, 26, 211-231. [CrossRef]

28. Jaafreh, A.B. The Effect Factors in the Adoption of Internet of Things (IoT) Technology in the SME in KSA: An Empirical Study. Int. Rev. Manag. Bus. Res. 2018, 7, 135-148.

29. Lewis, W.; Agarwal, R.; Sambamurthy, V. Sources of influence on beliefs about information technology use: An empirical study of knowledge workers. MIS Q. 2003, 27, 657-678. [CrossRef]

30. Park, S.; Chung, K. The Effect of Consumer Innovativeness, Perceived Risk and Price Sensitivity on New Product Adoption: The Moderating Effect of Gender. J. Internet Electron. Commer. Res. 2016, 16, 99-114.

31. Aldás-Manzano, J.; Lassala-Navarré, C.; Ruiz-Mafé, C.; Sanz-Blas, S. The role of consumer innovativeness and perceived risk in online banking usage. Int. J. Bank Mark. 2009, 27, 53-75. [CrossRef]

32. Liang, L.J.; Choi, H.C.; Joppe, M. Understanding repurchase intention of Airbnb consumers: Perceived authenticity, electronic word-of-mouth, and price sensitivity. J. Travel Tour. Mark. 2018, 35, 73-89. [CrossRef]

33. Reniers, R.L.; Murphy, L.; Lin, A.; Bartolomé, S.P.; Wood, S.J. Risk perception and risk-taking behaviour during adolescence: The influence of personality and gender. PLoS ONE 2016, 11, e0153842. [CrossRef] [PubMed]

34. Lima, M.L.; Barnett, J.; Vala, J. Risk perception and technological development at a societal level. Risk Anal. 2005, 25, 1229-1239. [CrossRef]

35. Martínez-Peña, R.M.; Hoogesteijn, A.L.; Rothenberg, S.J.; Cervera-Montejano, M.D.; Pacheco-Ávila, J.G. Cleaning products, environmental awareness and risk perception in Mérida, Mexico. PLoS ONE 2013, 8, e74352. [CrossRef]

36. Tseng, M.C.M.; Lin, Y.P.; Hu, F.C.; Cheng, T.J. Risks perception of electromagnetic fields in Taiwan: The influence of psychopathology and the degree of sensitivity to electromagnetic fields. Risk Anal. 2013, 33, 2002-2012. [CrossRef]

37. Hair, J.F., Jr.; Babin, B.; Money, A.H.; Samouel, P. Essential of Business Research Methods; John Wiley \& Sons: New York, NY, USA, 2003.

38. Comrey, A.L.; Lee, H.B. A First Course in Factor Analysis; Lawrence Eribaum Associates Inc.: Hillsdale, NJ, USA, 1992.

39. Tabachnick, B.G.; Fidell, L.S. Using Multivariate Statistics; Harper Collins: New York, NY, USA, 1996.

40. Liao, T.F. Interpreting Probability Models: Logit, Probit, and Other Generalized Linear Models; Sage: Newcastle upon Tyne, UK, 1994.

41. Harrell, F.E. Ordinal logistic regression. In Regression Modeling Strategies; Springer: Cham, Switzerland, $2015 ;$ pp. 311-325.

42. Hill, R.C.; Griffiths, W.E.; Lim, G.C. Principles of Econometrics; John Wiley \& Sons: New York, NY, USA, 2018. 
43. Kotsiantis, S.B. Local ordinal classification. In IFIP International Conference on Artificial Intelligence Applications and Innovations; Springer: Boston, MA, USA, 2006; pp. 1-8.

44. Hornung, R. Ordinal forests. J. Classif. 2020, 37, 4-17. [CrossRef]

45. Mansfield, E.R.; Helms, B.P. Detecting multicollinearity. Am. Stat. 1982, 36, 158-160.

46. Bhattacherjee, A. Understanding information systems continuance: An expectation-confirmation model. MIS Q. 2001, 25, 351-370. [CrossRef]

47. Oliver, R.L. A cognitive model of the antecedents and consequences of satisfaction decisions. J. Mark. Res. 1980, 17, 460-469. [CrossRef]

48. LG U+. IoT Packages: Switch IoT. Available online: https:/ /www.uplus.co.kr/ent/iot/IoTSwitchInfo.hpi (accessed on 19 May 2019).

49. Moon, H.B. Analysis on Consumer Information Search Behavior for Search and Experience Goods. Master's Thesis, Seoul National University, Seoul, Korea, 2014.

50. East, R.; Uncles, M.D.; Lomax, W. Hear nothing, do nothing: The role of word of mouth in the decision-making of older consumers J. Mark. Manag. 2014, 30, 786-801. [CrossRef]

51. Kimmel, A.J.; Kitchen, P.J. WOM and social media: Presaging future directions for research and practice. J. Mark. Commun. 2014, 20, 5-20. [CrossRef]

52. Czepiel, J.A. Word-of-mouth processes in the diffusion of a major technological innovation. J. Mark. Res. 1974, 11, 172-180. [CrossRef]

53. Seock, Y.K.; Bailey, L.R. The influence of college students' shopping orientations and gender differences on online information searches and purchase behaviours. Int. J. Consum. Stud. 2008, 32, 113-121. [CrossRef]

54. Bae, S.; Lee, T. Gender differences in consumers' perception of online consumer reviews. Electron. Commer. Res. 2011, 11, 201-214. [CrossRef]

55. Venkatesh, V.; Morris, M.G.; Davis, G.B.; Davis, F.D. User acceptance of information technology: Toward a unified view. MIS Q. 2003, 27, 425-478. [CrossRef] 